Mater. Res. Soc. Symp. Proc. Vol. $1529 \bigcirc 2013$ Materials Research Society

DOI: $10.1557 / 0 p l .2013 .249$

\title{
Fabrication of Large-Area Organic Photovoltaics Using a Draw-Bar Coating Technique
}

\author{
Cara J. Mulligan', Nicolas C. Nicolaidis ${ }^{1,2}$, Ben Vaughan ${ }^{1,2}$, Xiaojing Zhou ${ }^{1}$, Warwick J.
} Belcher $^{1}$ and Paul C. Dastoor ${ }^{1}$

${ }^{\prime}$ Centre for Organic Electronics, University of Newcastle, Callaghan, NSW 2308, Australia.

${ }^{2}$ CSIRO Energy Centre, Mayfield West, NSW 2304, Australia.

\begin{abstract}
Organic photovoltaic (OPV) devices were fabricated using a novel draw bar premetered coating technique, whereby a meniscus of fluid is dragged across a substrate to leave a trailing wet film. The results showed that coating thickness could be controlled by varying the coating speed, rod diameter, gap height, amount of solution injected, rod diameter, rod composition material and number of layers. Devices on PET with active areas of $10 \mathrm{~cm}^{2}$ and active layer thicknesses ranging from 35 to $475 \mathrm{~nm}$ were produced using the technique. Active layers of 160 nm were the optimum of thicknesses trialled, achieving typical best efficiencies around $0.4 \%$. Devices with films thinner than $90 \mathrm{~nm}$ did not function due to short-circuiting. The draw-bar coating method has the advantage of allowing controlled deposition of a wide range of film thicknesses with no solution wastage.
\end{abstract}

\section{INTRODUCTION}

Organic photovoltaic (OPV) devices for harvesting solar energy have the potential to be a widely adopted source of sustainable electricity for a range of applications. The devices can be solution processed; therefore inexpensive reel-to-reel printing and coating techniques are being investigated as a means of mass-producing OPV devices.

There are a wide variety of conventional printing and coating techniques that have been applied to large area OPV fabrication, including slot die ${ }^{1,2}$, knife over edge $^{1}$, screen printing ${ }^{1}$, gravure printing ${ }^{3,4,5}$ and spray coating ${ }^{6}$.

Although some existing printing and coating techniques have successfully produced large area $\mathrm{OPV}$, there is motivation to develop and explore novel techniques that may offer advantages such as reduced solution wastage, improved active layer thickness and patterning control, simpler design and more consistent substrate coverage leading to better yields. The novel coating technique examined in this paper was developed with the goal of incorporating these advantages, and this paper aims to explore the performance of the technique with respect to thickness control and consistency of the coated films. This work also demonstrates the successful production of large-area devices using the technique.

\section{EXPERIMENT}

The coating technique employed in this work has been termed "draw-bar coating", and consists of a substrate being passed by a fixed cylindrical rod held several hundred microns from the surface. The coating fluid is introduced in the gap between the rod and substrate and the resulting meniscus is dragged along by the relative movement of the substrate and rod, depositing a trail of fluid. The amount of fluid in the meniscus can be held constant by 
continuously trickling additional fluid onto the rod where it flows into the meniscus.

Additionally, the gentle nature of the technique means that all of the fluid is deposited onto the substrate and there is almost no solution wastage. Figure 1 illustrates the coating process and a typical meniscus shape.

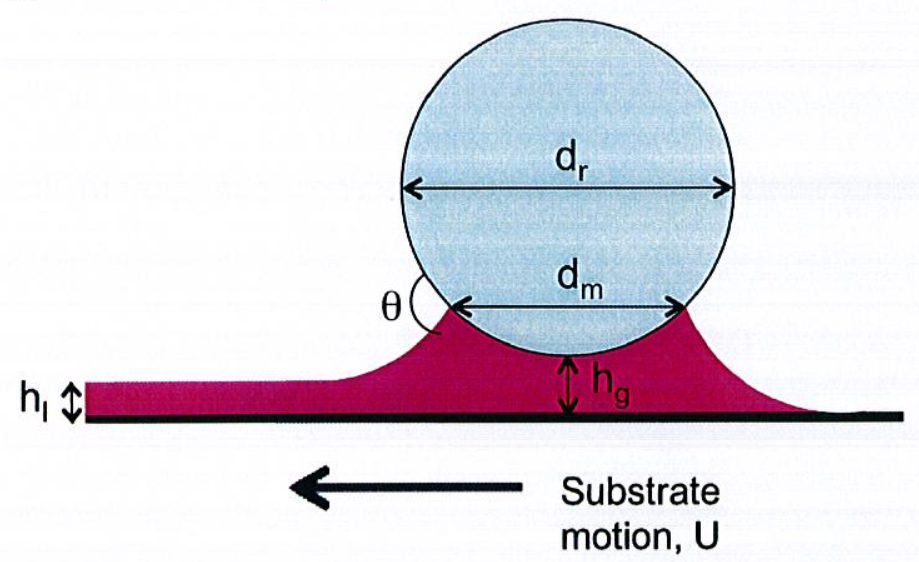

Figure 1: Diagram of coating technique showing rod diameter $\left(d_{r}\right)$, meniscus width $\left(d_{m}\right)$, gap height $\left(h_{\mathrm{g}}\right)$, film height $\left(\mathrm{h}_{\mathrm{l}}\right)$ and rod/fluid contact angle $(\theta)$.

The coating is governed by the Landau Levich Derjaguin regime ${ }^{7}$, which indicates that coating thickness $\left(h_{1}\right)$ follows a $2 / 3$ power relationship with respect to the coating velocity. Neglecting the influence of the coating rod, the coating thickness is related to the coating speed (U), fluid viscosity $(\mu)$ and surface tension $(\sigma)$, according to:

$$
h_{l}=0.945 l_{c} C a^{2 / 3} \quad \text { where } l_{c}=\sqrt{\frac{\sigma}{\rho g}} \text { and } C a=\frac{\mu U}{\sigma}
$$

where $\mathrm{Ca}$ is the capillary number which represents the ratio of viscous effects to surface tension and $l_{c}$ is the capillary length which is the critical length where gravity becomes significant in a fluid system. Equation 1 was developed for dip coating, a similar coating method where the substrate is drawn out of liquid rather than liquid drawn across the substrate and therefore does not consider effects of gap height, rod diameter, meniscus width and rod/solution contact angle. This equation is useful for predicting the relationship between velocity and coating thickness for draw-bar coating, while the impact of the other parameters can instead be measured empirically.

Experimentally, the coating thickness was controlled by varying the coating speed (U), rod diameter $d_{r}$, gap height $h_{g}$, amount of solution injected, rod/fluid contact angle $\theta$ (controlled by the rod material) and number of coating passes. Table I outlines the range of coating parameters trialled for active layer deposition, where the active layer consisted of P3HT:PCBM (1:1) at 25 $\mathrm{mg} / \mathrm{mL}$ in chloroform. Only one parameter was changed at a time and all other parameters were held at the standard values as quoted in Table I. The viscosity of the active layer was $2.5 \mathrm{mPa} . \mathrm{s}$ and the surface tension of chloroform was $0.027 \mathrm{~N} / \mathrm{m}$. The static rod/fluid contact angle was measured for teflon, steel and glass surfaces using the sessile drop method on a Dataphysics OCA20 tensiometer. Film thicknesses were measured using a KLA Tencor Alpha Step 500 
profilometer and the sample size was eight measurements for each parameter, leading to 264 total samples.

Table I: Range of parameters trialled for active layer deposition.

\begin{tabular}{|l|l|l|}
\hline Parameter & Range Trialled & Standard Value \\
\hline Coating speed & $0.05-5.7 \mathrm{~cm} / \mathrm{s}$ & $0.5 \mathrm{~cm} / \mathrm{s}$ \\
\hline Gap height & $150-580 \mu \mathrm{m}$ & $330 \mu \mathrm{m}$ \\
\hline Rod diameter & $12 \mathrm{~mm} \& 100 \mathrm{~mm}$ & $12 \mathrm{~mm}$ \\
\hline Rod/fluid contact angle & $3-22^{\circ}$ & $12^{\circ}$ \\
\hline Solution amount & $15-60 \mu \mathrm{L}$ & $\begin{array}{l}30 \mu \mathrm{L}(+15 \mu \mathrm{L} \text { added for each } \\
\text { subsequent coat in multiple pass trials) }\end{array}$ \\
\hline Coating passes & $1-6$ & 1 \\
\hline
\end{tabular}

In this work OPV devices were fabricated on $0.1 \times 0.1 \mathrm{~m}$ substrates and consisted of six device fingers each with dimensions of $0.1 \times 0.01 \mathrm{~m}$. For the purpose of this work each finger was electrically isolated and tested independently such that the total area of each device was $10 \mathrm{~cm}^{2}$. Figure 2 shows coated substrates before and after cathode deposition and the module dimensions. The substrates used were ITO coated PET with nominal resistance of $14 \Omega / \square$, which was manually patterned to allow six isolated cells to be fabricated. The draw-bar coating method was used to firstly deposit a layer of PEDOT:PSS onto the substrate at a coating speed of $1 \mathrm{~mm} / \mathrm{s}$ with $0.3 \mathrm{~mm}$ gap height, $12 \mathrm{~mm}$ diameter steel rod and $15 \mu \mathrm{L}$ of solution injected. Substrates were then dried at $50^{\circ} \mathrm{C}$ for 15 mins. This was followed by draw-bar coating the active solution of P3HT:PCBM (1:1) dissolved in chloroform at a concentration of $25 \mathrm{mg} / \mathrm{mL}$. Coating was conducted under the standard conditions outlined in Table 1, except multiple passes were carried out to deposit more than one layer. The number of passes was varied from $1-6$ passes to achieve a range of six different film thicknesses between 35 to $475 \mathrm{~nm}$. Lastly $20 \mathrm{~nm}$ of calcium and $80 \mathrm{~nm}$ of aluminium were evaporated to form the cathode. Devices were tested under AM1.5 conditions to produce IV curves, with voltage varied from -0.2 to $0.8 \mathrm{~V}$. From these curves, the series resistance was measured as the reciprocal of the gradient at the open-circuit voltage. The total sample size was 120 devices fabricated, ie. 20 repeats at each of the six thicknesses trialled.

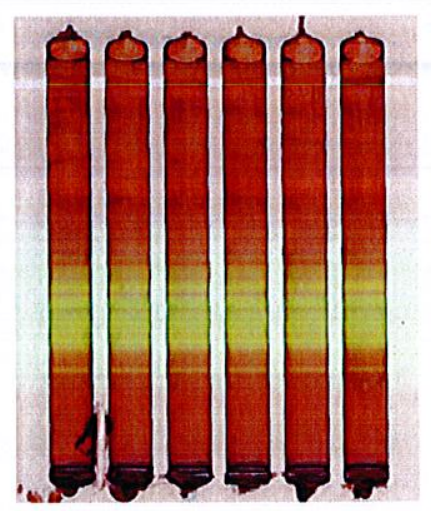

A

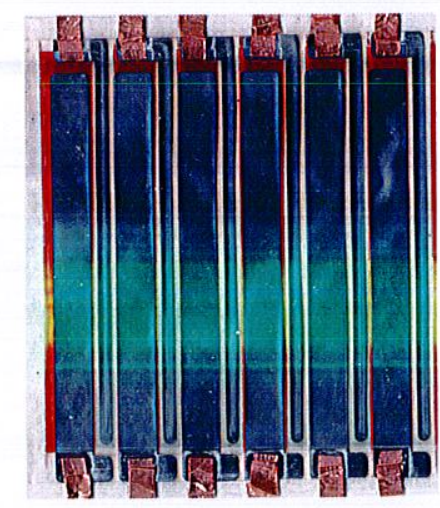

B

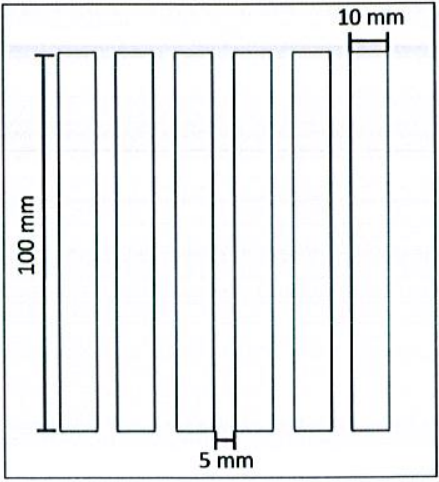

C

Figure 2: Draw bar coated devices, A: before cathode evaporation, B: with cathode (cathode side up), C: sketch showing device active area dimensions. 


\section{RESULTS}

Variations in each coating parameter outlined earlier produced films of different thicknesses, with the relationships shown in Figure 3a-e.
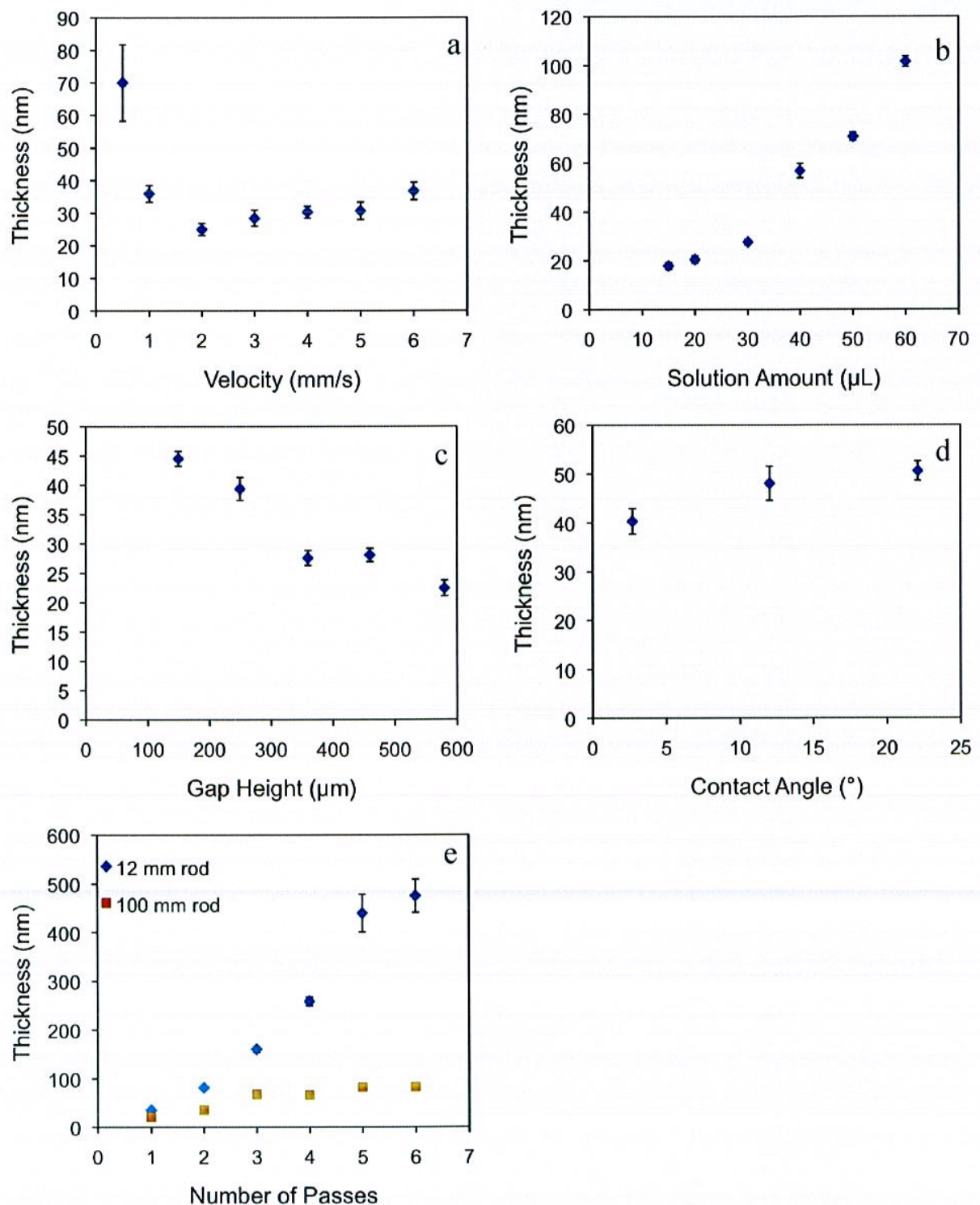

Figure 3: Effect of coating parameters on final film thickness for a) coating velocity, b) solution volume injected, c) gap height between meniscus and substrate, d) static rod/fluid contact angle and e) number of coating passes. 
As shown in Figure 3a, the coating velocity and film thickness relationship is non-linear, producing the thinnest films at $2 \mathrm{~mm} / \mathrm{s}$. As predicted by Equation 1, progressively thicker films were observed when coating velocities were increased above $2 \mathrm{~mm} / \mathrm{s}$, due to the increased viscous stresses causing a thicker wet layer to remain behind the meniscus ${ }^{7,8}$. On the other hand, when velocities were below $2 \mathrm{~mm} / \mathrm{s}$ the coating becomes thicker as speeds are reduced. The deviation from the Landau Levich Derjaguin regime may be due to the high volatility of the fluid causing the drying front to occur very close to the meniscus where the wet layer is thicker'. The remaining coating parameters investigated are not present in Equation I as it was developed for dip coating, so the concepts of gap height, rod diameter and injected solution do not apply. These coating relationships showed generally linear behaviour. An increase in meniscus contact width $\left(d_{m}\right)$ with the substrate was also correlated with an increase in film thickness. This was achieved by either increasing the amount of fluid injected (Figure $3 \mathrm{~b}$ ) or reducing the gap height $\left(h_{g}\right)$ between the rod and the substrate (Figure 3c). As shown in Figure 3d, higher rod/fluid contact angles $(\theta)$ increased the film thickness due to the fluid having a lesser affinity for wetting the rod, changing the dynamic wetting line and therefore the coating behaviour ${ }^{10}$. Finally, as shown in Figure 3e, the film thickness resulting from the use of two different rod diameters $\left(d_{r}\right)$ showed the $12 \mathrm{~mm}$ rod diameter resulted in thicker films than the $100 \mathrm{~mm}$ diameter rod, with the difference being more pronounced as further layers were deposited. The larger diameter rod causes a greater meniscus contact area with the substrate, so in cases where multiple coating passes are being conducted there is more time for an existing active layer to be redissolved as the meniscus passes over. The number of coating passes (ie. layers deposited) had the greatest impact on final film thickness and permitted the largest range of thicknesses to be achieved when using the standard $12 \mathrm{~mm}$ diameter rod.

As good control of film thickness could be achieved, and film thickness is known to influence OPV performance ${ }^{11}$, devices with active layer thicknesses ranging from 35 to $475 \mathrm{~nm}$ were produced. Example JV curves of four typical devices with different thickness of active layer are shown in Figure 4 and average device performances are given in Table II. The optimum thickness in this work was around $160 \mathrm{~nm}$, with these devices achieving typical best efficiencies of $0.4 \%$. Devices below around $90 \mathrm{~nm}$ in thickness did not function because of short-circuiting. As demonstrated by Table 2, there is a general reduction in performance that can be observed when device thickness increases above $160 \mathrm{~nm}$. In particular, the series resistance increase with thickness is a contributing factor to the corresponding decreasing fill factor ${ }^{12}$. The findings of [11] show that for devices on glass with thicknesses ranging from $70-330 \mathrm{~nm}$ a maximum efficiency of $3.7 \%$ was achieved at a thickness of at $225 \mathrm{~nm}$, with a $260 \mathrm{~nm}$ device having a higher efficiency than a $160 \mathrm{~nm}$ device. This contrasts with the findings of this work, where the $160 \mathrm{~nm}$ device performed better than the $260 \mathrm{~nm}$ device and all other thicker devices (other devices in this work could not be compared as they were outside the range tested in [11]). This difference may be due to ITO on PET being much rougher than on ITO on glass, as evidenced by the short circuiting of PET devices below $90 \mathrm{~nm}$ thickness compared with glass substrate devices gaining efficiencies of $\sim 2 \%$ at thicknesses of $70 \mathrm{~nm}^{11}$. 


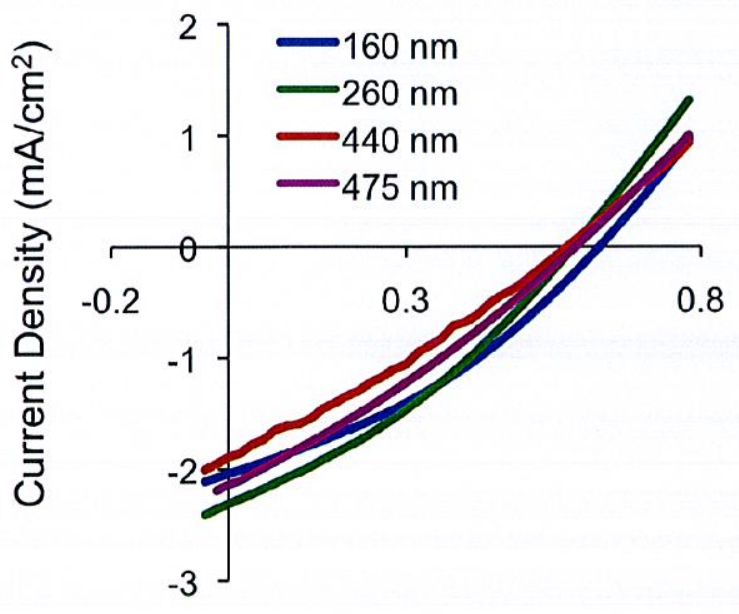

Voltage (V)

Figure 4: Example of JV curves for working devices.

Table II: Average device performance for different active layer thicknesses.

\begin{tabular}{|l|l|l|l|l|l|}
\hline $\begin{array}{l}\text { Thickness } \\
(\mathbf{n m})\end{array}$ & Efficiency $(\%)$ & $\mathbf{V}_{\mathbf{O C}}(\mathbf{V})$ & $\mathbf{J}_{\mathbf{S C}}\left(\mathbf{m A} \mathbf{A} \mathbf{c m}^{2}\right)$ & $\begin{array}{l}\text { Fill } \\
\text { Factor }\end{array}$ & $\begin{array}{l}\text { Series } \\
\text { Resistance }(\Omega)\end{array}$ \\
\hline$<90$ & 0 & 0 & 0 & 0 & n/a \\
\hline 160 & 0.32 & 0.55 & -1.87 & 0.31 & 18.6 \\
\hline 260 & 0.28 & 0.47 & -1.86 & 0.30 & 20.4 \\
\hline 440 & 0.23 & 0.46 & -1.66 & 0.29 & 21.6 \\
\hline 475 & 0.22 & 0.47 & -1.62 & 0.28 & 23.7 \\
\hline
\end{tabular}

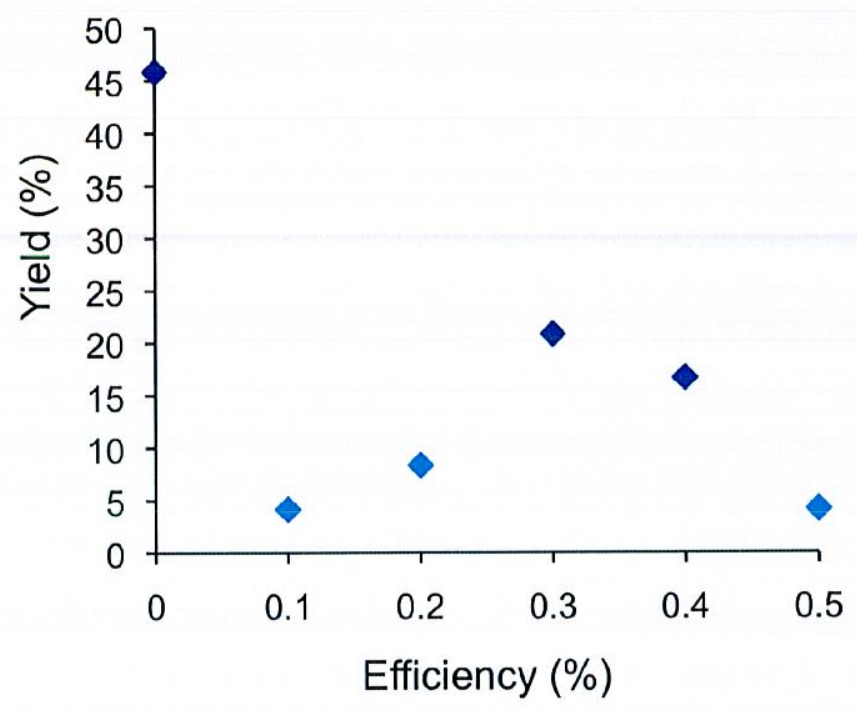

Figure 5: Device yield vs efficiency for all devices with active layer thicknesses $160 \mathrm{~nm}$ and above (to nearest $0.1 \%$ ). 
Device yields over different efficiency ranges are presented in Figure 5 for devices with active layer thicknesses greater than or equal to $160 \mathrm{~nm}$. The high yield of short-circuited devices, approaching $45 \%$ for devices with active layer thicknesses $160 \mathrm{~nm}$ or more (and $100 \%$ for those below $90 \mathrm{~nm}$ ) indicates that there may be problems with consistency on the non-uniform ITO substrates.

\section{CONCLUSIONS}

This work demonstrated that the novel draw-bar coating method allows controlled deposition of a wide range of film thickness and can successfully be used to manufacture largearea devices. Efficiencies of $0.4 \%$ were achieved for a typical working P3HT:PCBM device with a continuous active area of $10 \mathrm{~cm}^{2}$ and active layer thickness around $160 \mathrm{~nm}$. Advantages of the technique include almost no solution wastage and simple design. Further work to better understand the coating behaviour and improve device efficiencies and yields is ongoing.

\section{REFERENCES}

1. F.C. Krebs Sol. Energ. Mat. Sol. Cells 93: 465-475 (2009)

2. L. Blankenburg, K. Schultheis, H. Schache, S. Sensfuss and M. Schrödner Sol. Energ. Mat. Sol. Cells 93: 476-483 (2009)

3. J.M. Ding, A.F. Vornbrock, C. Ting, and V. Subramanian Sol. Energ. Mat. Sol. Cells 93: 459-464 (2009)

4. P. Kopola, T. Aernouts, S. Guillerez, H. Jin, M. Tuomikoski, A. Maaninen and J. Hast Sol. Energ. Mat. Sol. Cells 94: 1673-1680 (2010)

5. P. Kopola, T. Aernouts, R. Sliz, S. Guillerez, M. Ylikunnari, D. Cheyns, M. Välimäki, M. Tuomikoski, J. Hast, G. Jabbour, R. Myllylä and A. Maaninen Sol. Energ. Mat. Sol. Cells 95: 1344-1347 (2011)

6. S. Park, Y. Kang, S. Lee, D. Kim, J.-K. Kim, J.-H. Kim and J. Kang Sol. Energ. Mat. Sol. Cells 95: 852-855 (2011)

7. V.G. Levich Physicochemical Hydrodynamics Prentice Hall, Englewood Cliffs, N.J., 2nd edition (1962)

8. G.F. Teletzke, H.T. Davis and L.E. Scriven Rev. Phys. Appl. 23: 989-1007 (1988)

9. G. Berteloot, C.-T. Pham, A. Daerr, F. Lequeux and L. Limat Europhys. Lett. 83(1): 14003 (2008)

10. H.M. Thompson, N. Kapur, P.H. Gaskell, J.L. Summers and S.J. Abbott Chem. Eng. Sci. 56: 4627-4641 (2001)

11. A.J. Moulé, J.B. Bonekamp and K. Meerholz J. Appl. Phys. 100: 094503 (2006)

12. C. Winder and N. S. Sariciftci J. Mater. Chem. 14: 1077-1086 (2004) 